\title{
Sustainable product purchase: does information about product sustainability on social media affect purchase behavior?
}

\author{
Muhammad Amad Saeed ${ }^{1 *}$, Ammara Farooq ${ }^{2}$, Wolfgang Kersten ${ }^{1}$ and Semah Ibrahim Ben Abdelaziz ${ }^{1}$
}

\author{
* Correspondence: muhammad. \\ saeed@tuhh.de \\ ${ }^{1}$ Hamburg University of Technology, \\ Institute of Business Logistics and \\ General Management, Am \\ Schwarzenberg Campus 4, 21073 \\ Hamburg, Germany \\ Full list of author information is \\ available at the end of the article
}

\begin{abstract}
Nowadays, consumer-to-consumer communication and its impact on purchase decisions have gained substantial consideration owing to digitalization and the emergence of internet-based social media platforms. Social media allows consumers to communicate with thousands of people well beyond their network. Consequently, the demand for transparency from industrial corporations has increased. It even becomes more important to understand how sustainability-related information on social media holds organizations accountable for their wrongdoings and reward them for taking sustainability-related initiatives. In this research work, the authors investigate how information that is available on social media influences consumers' purchase behavior with regard to sustainable products in the context of developing countries. Therefore, the authors surveyed social media users residing in Pakistan and used partial least squares structural equation modeling (PLS-SEM) to analyze the collected data. The results established that positive and negative sustainability-related information on social media significantly influences consumers' intention to purchase sustainable products. Furthermore, this study explains that consumers' willingness to seek sustainabilityrelated information makes them dependent on social media and this dependency on social media affects their intention to purchase.
\end{abstract}

Keywords: Sustainable product development, Social media, Consumer purchase behavior, Sustainability risk, Sustainability trust, Media system dependency theory

\section{Introduction}

Digitalization and the transparency that new forms of media, such as the internet and social media, offer, revolutionize how consumers communicate with each other (Buzzetto-More 2013; Men and Tsai 2013). This increased transparency grants consumers more access to information associated with product usage and spreads awareness relating to the conditions under which industrial corporations produce the products. This has not only resulted in an increase in the sales of sustainable products (Nielsen 2015), but also pressurizes organizations to address environmental, as well as social sustainability-related issues that their operations cause, and to adopt sustainability practices across their whole supply chain network.

According to Saeed and Kersten (2017), sustainability goals in the context of supply chain management are "to render maximum value to all stakeholders and fulfill customer requirements by achieving sustainable flows of products, services, information,

(c) The Author(s). 2019 Open Access This article is distributed under the terms of the Creative Commons Attribution 4.0 International License (http://creativecommons.org/licenses/by/4.0/), which permits unrestricted use, distribution, and reproduction in any medium, provided you give appropriate credit to the original author(s) and the source, provide a link to the Creative Commons license, and indicate if changes were made. 
and capital as well as cooperation among supply chain participants." The consumers' and other stakeholders' sustainability-related expectations require that organizations incorporate sustainability throughout their supply chain by shifting their focus from traditional profit-seeking toward addressing ecological and social sustainability-related issues (Carter and Easton 2011; Hervani et al. 2005; Saeed and Kersten 2017). Seuring and Müller (2008), however, defined sustainability in the product context as "a term used to comprehend all kinds of products that have or aim at an improved environmental and social quality (...). The ultimate aim is to satisfy customers and gain a competitive advantage in the market." Therefore, to achieve improved environmental and social quality, organizations need to introduce sustainability during the product development stage in which all the product's substantial features and properties are defined (Petersen 2017).

The significant rise in the number of internet users over the years causes a paradigm shift in consumers' behavior all over the world and establishes a changing trend in the consumers' readiness to seek information from new channels of mass communication, such as social media (Men and Tsai 2013). Consequently, the use of the internet and social media tends to influence consumers' purchase behavior, as it allows consumers to interact with other consumers, and companies to interact with existing and potential customers. In developed countries like Germany, the 2014 survey results show that information on social media has already influenced the purchase decision of more than 6\% of German customers (Berger 2014).

Despite social media's growing importance, the scientific literature that investigates how information that is available on social media influences consumers' purchase behavior with regard to sustainable products, is scant. Particularly in developing countries, scientific literature has not extensively addressed information seeking on social media pertaining to the sustainability of products, brands, or services, and how it affects consumer purchase decisions. Although sustainability has become a global issue of importance (Jaiswal and Kant 2018; Saeed and Kersten 2019), European companies are commonly assumed to be more keen to adopt sustainability practices and report their sustainability performance (KPMG 2015). Furthermore, the sustainability-related scientific literature focuses to a great extent on developed countries (Jaiswal and Kant 2018; Saeed and Kersten 2019); in developing countries, consumers are less aware of sustainability issues and sustainable products than consumers in developed countries (Altarawneh 2013; Butt 2017; Darley and Johnson 1993; Mohiuddin et al. 2018). Moreover, studies related to sustainable purchase behavior in developing countries are scarce (Jaiswal and Kant 2018; Joshi and Rahman 2019). This dearth of scientific literature and consumers' awareness emphasize the importance to identify how, in developing countries, sustainability-related information on social media acts as the conscience of businesses and holds them responsible for their wrongdoings and reward them for doing things right. Hence, in order to broaden all perspectives, the authors developed a conceptual model to investigate how information available on social media influences consumers' purchase behavior in Pakistan with regard to sustainable products. In light of media system dependency theory (MSD), this study investigates sustainability-related information seeking on social media and its effect on consumers' intention to purchase, while considering the impact of perceived risk and trust on social media. 
In Literature review and hypotheses development section, the authors explain the concepts of social media and media system dependency theory and, furthermore, give a detailed literature review of how the research hypotheses developed. In Methodology and measurement section, the authors describe the methodology along with the measurement of constructs, while Findings and analysis section presents the results of the research work, using PLS-SEM, followed by the conclusion in Conclusions and outlook section.

\section{Literature review and hypotheses development}

\section{Social media}

The continuous exponential increase in internet and social media usage has made them major sources of business-related information, particularly with regard to products and brands (Buzzetto-More 2013). According to the international telecommunication union (ITU), half of the world's entire population, i.e. 4.4 billion persons, use the internet, and of them, 3.5 billion persons are social media users (Statista 2019). However, the percentage of young people aged $15-24$ using the internet $(71 \%)$ is much higher than the percentage of the total population using the internet (48\%) (ITU 2017). Although the percentage of the total number of active internet users in developed countries is higher than that of developing countries, the gap decreases rapidly, with a specific increase in the number of active internet users in developing countries like China and India. Similarly, in Pakistan, at the end of $2016,16 \%$ of the population, i.e. 30 million persons, had access to the internet, which was almost double the total number of internet users in 2010, i.e. 16 million persons.

Internet and social media users can access product or brand-related sustainability information, which individuals, NGOs, and other consumer groups make available, in the form of blogs, discussion forums, cooperative projects (e.g., Wikipedia), content communities (e.g., YouTube), product rating or ranking websites (e.g., rankabrand.org), and other social networking websites (Kaplan and Haenlein 2010; Men and Tsai 2013; Reilly and Weirup 2012). Likewise, internet and social media offer organizations new opportunities to interact with a large pool of customers and influence consumers' purchase decisions (Buzzetto-More 2013; Dei Worldwide 2008). Kaplan and Haenlein (2010) defined social media as "a group of internet-based applications that build on the ideological and technological foundations of Web 2.0, and that allow the creation and exchange of user-generated content."

Social media users create, share, and consume the product or brand-related content with the intention of educating each other about a company's sustainable practices and its supply chain (Ngai et al. 2015; Xiang and Gretzel 2010). These consumers' opinions, comments, and sharing of personal, product sustainability-related experiences on social media lead to an increase in the perceived word of mouth (WOM) (Buzzetto-More 2013; Xiang and Gretzel 2010). Consumers consider this WOM more trustworthy and reliable than information from traditional sources of mass communication, such as advertisements and company-initiated communications in newspapers and magazines (Brown et al. 2007). Due to these characteristics, social media-generated WOM has enormous potential to go viral and might influence many receivers (Brown et al. 2007; Buzzetto-More 2013). Satisfied customers may act as brand ambassadors and spread positive WOM, and unsatisfied customers may turn against a product or brand and spread negative WOM. Consequently, negative and positive social media-initiated 
WOM can potentially impact the customers' intention with regard to purchasing products or brands (Buzzetto-More 2013; Gáti and Markos-Kujbus 2012; Grégoire et al. 2015) and holding businesses accountable for promises they made.

\section{Media system dependency theory}

Recent developments and outreach have introduced social media as an instance of mass media (Kheiravar 2018). In order to identify how the use of social media as an information medium can influence consumers' cognitive and affective beliefs pertaining to sustainable product purchase, the authors select the well-established media system dependency theory (MSD) as a theoretical framework in this research work. MSD builds on the distinguishing and pivotal conceptualization of media dependency relations, which provides a solid theoretical understanding of individuals' motivations for using media, and its consequences (Ben Abdelaziz et al. 2015; Kheiravar 2018). BallRokeach and DeFleur (1976) defined dependency as "a relationship in which the satisfaction of needs or the attainment of goals by one party is contingent upon the resources of another party."

The core premise of MSD is that media can only exert powerful influence if consumers develop a dependency relationship to seek information through it (Jung and Moro 2012; Kheiravar 2018), whereas the amount of time the audience spends on the medium explains the audience dependency on the medium (Ball-Rokeach and DeFleur 1976). Higher dependency on the medium is also considered as a result of meeting an individual's needs via the medium (Kheiravar 2018). In the MSD view, media has two levels of dependency relations, i.e. with individuals (micro-level) and with other systems (macro-level), such as economic and political systems (Jung and Moro 2012). The micro-level dependency relations, also known as individual media system dependency, focus on the relationship between media and individuals (Kheiravar 2018). Micro-level dependency is the evaluation of the individuals' motivation to seek information via the media (Ben Abdelaziz et al. 2015), whereas the macro-level dependency explains the interdependencies among the audience, media, and society. At the macro-level, analyzing the macro origins of dependencies explains the effects of individual media dependency relations (Kheiravar 2018).

However, in the case of social media, its characteristics enable it to move across levels. At the micro-level, users generate content, which they can share publicly at the macro-level (Jung and Moro 2012). As MSD postulates that media may cause cognitive, affective, and behavioral changes in individuals who are exposed to them (Ball-Rokeach and DeFleur 1976), this research article investigates how a dependency on social media for sustainability-related information can influence consumers' purchase intention.

\section{Theoretical relationships and hypotheses development}

The global focus of manufacturing and service industries has shifted to devise strategies for reducing the undesirable environmental and societal impacts of these industries' product development processes (Ribeiro and Kruglianskas 2013). Organizations are considered to be more responsible and expected to go beyond the boundary of traditional profit-seeking thinking toward more ecological and socially responsible businesses. Furthermore, regulatory requirements and a multitude of stakeholder and 
consumer expectations force companies to take sustainability initiatives in order to overcome the sustainability-related issues their operations cause (Carter and Easton 2011; Saeed and Kersten 2019). In their research, Chen and Chang (2012) identified that green sustainability-related performance leads to purchase intention.

Although previous research empirically supported the media dependency's positive effects on purchase intention, consumers are reluctant to buy products if they perceive themselves lacking sufficient information to make the right purchase decisions (Ben Abdelaziz et al. 2015). Traditional offline communication channels either do not offer such information or information retrieval is far more difficult, which leads to consumer confusion (Mitchell and Papavassiliou 1999). However, online social media platforms provide more enriched and easier to retrieve user-generated information, which can have a substantial impact on consumers' purchase behavior. In accordance with this article's research objective, i.e. to investigate how sustainability-related information on social media influences consumers' intention to purchase, the authors develop the following hypotheses.

\section{Willingness to seek sustainability-related information and dependency on social media}

The consumers' willingness to seek sustainability-related information depends on the consumers' willingness to change their state of sustainability knowledge. As stated, social media provides detailed and enriched sustainability-related information and it is very likely that consumers who are willing to seek this kind of information become dependent on social media. Owing to consumers' increased social media usage, marketers also expand their social media presence to attract users and to build long-term relationships with them through various channels (Jaiswal and Singh 2018).

Furthermore, social media users' interaction with other group members enables them to shape their perception of buying sustainable products. According to Ben Abdelaziz et al. (2015), motivated consumers who consider online resources (e.g., social media) useful, will very likely become dependent on them. The discussion on social media platforms allows consumers to inadvertently start approving, as well as disapproving, a product or a brand, which enables the consumers to trust the source of the information and make them dependent on social media for obtaining guidance with regard to their sustainable product purchase decisions (Ben Abdelaziz et al. 2015). Hence, the authors formulate the first hypothesis as follows -

H1: Willingness to seek sustainability-related information positively influences the dependency on social media for sustainability-related information.

\section{Dependency on social media for sustainability-related information and intention to purchase}

The consumers' lack of knowledge regarding a particular product in order to make the right purchase decision, prevents them from engaging in purchasing. This, in turn, might influence the consumers' product choice and result in postponing, as well as halting, the purchase in order to avoid cognitive strain (Mitchell and Papavassiliou 1999). Furthermore, according to the literature, detailed verbal information regarding environmentally friendly products helps educate consumers, which, in turn, positively 
influences consumers' intention to purchase sustainable products (Gleim et al. 2013). The information usefulness of online user-generated content is considered to be more effective than traditional marketer-generated content (Buzzetto-More 2013).

Social media comprises communication websites that facilitate the development of relationships between internet users who have diverse backgrounds. The consumer-generated, product-related information on social media helps other potential consumers in their decisions to buy or not buy a product (Carillo et al. 2017). Ben Abdelaziz et al. (2015) defined dependency on social media for sustainability-related information as "individuals' contingency upon social media information resources in order to attain their objectives of making the right decisions when it comes to purchasing sustainable products or brands." Relating to the previous arguments, social media offer a favorable situation for consumers by providing comprehensive information from multiple sources, whereby consumers might very likely become reliant on social media (Wang et al. 2017). Hence, the authors formulate the second hypothesis as follows -

H2: Dependency on social media for sustainability-related information positively influences the intention to purchase sustainable products.

\section{Social media information dependency and sustainability trust and risk on social media}

Social media has become vital in today's business world, as it allows consumers more freedom in sharing their opinion regarding products. The construct of sustainability trust is the tendency for and inclination toward a product that presumably receives affirmative statements with respect to sustainability features from former, actual, or potential consumers via social media on the basis of a belief in or expectation of the product's sustainability-related performance (Ben Abdelaziz et al. 2015). On the other hand, Ben Abdelaziz et al. (2015) define the construct of sustainability risk on social media as "the expectation of negative consequences affecting sustainability as a result of purchasing products or brands that have been exposed to negative statements by former, actual, or potential consumers on social media, concerning their sustainability features."

Academicians emphasized that the trust antecedents vary according to the communication type that occurs on social media (Chang et al. 2013; Laroche et al. 2012). They have also suggested that perceived information usefulness and information credibility create a tendency in social media users to adopt both positive and negative WOM (Cheung and Thadani 2012). Hence, it is possible to postulate that consumers who are dependent on social media are very likely to adopt affirmations and build a higher perceived trust in products that other social media users mention or discuss as sustainable. Likewise, consumers who are dependent on social media are more prone to negative statements regarding a product's sustainability performance and very likely to perceive products that received negative comments on social media as risky and relatively less sustainable. Hence, the authors formulate the third and fourth hypotheses as follows -

H3: Dependency on social media for sustainability-related information positively influences sustainability trust on social media. 
H4: Dependency on social media for sustainability-related information positively influences sustainability risk on social media.

\section{Sustainability risk on social media and intention to purchase}

The notion that perceived risk has a negative impact on the intention to purchase, is well established in the literature (Chang and Chen 2008; Grégoire et al. 2015; Kim et al. 2008; Mitchell and Papavassiliou 1999). Moreover, Chen and Chang (2012) showed that the perceived risk of harmful damage to the environment has a negative impact on the intention to purchase products. Social media users who perceive products with negative comments on social media as harmful, are presumably more aware of products or brands-related sustainability issues, and adopt other users' negative WOM about products' sustainability performance (Ben Abdelaziz et al. 2015).

Hence, it is possible to postulate that consumers are very likely to refrain from buying products or brands if they become aware of the product's or brand's negative sustainability performance; as a result, these consumers will rather purchase relatively more sustainable products or brands. Accordingly, the authors formulate the fifth hypothesis formulated as follows -

H5: Sustainability risk on social media positively influences the intention to purchase sustainable products.

\section{Sustainability trust on social media and intention to purchase}

In scientific literature, several authors think that perceived trust is a key driver of the intention to purchase (Chang and Chen 2008; Kim et al. 2008). Chen and Chang (2012) have also identified that perceived trust in better performing, environmentally sustainable products has a positive impact on the intention to purchase these products. Therefore, consumers are less likely to follow a product or brand when people do not predominantly like it, because consumers tend to follow a product or brand that is linked to positive WOM (Gáti and Markos-Kujbus 2012; Ladhari and Michaud 2015). Social media users who perceive products with positive recommendations on social media as sustainable, are presumably more aware of sustainability-related issues and adopt other users' positive WOM about the products' sustainability performance (Ben Abdelaziz et al. 2015). Hence, it is possible to postulate that consumers are very likely to buy products or brands if they become aware of the products' positive sustainability performance and that consumers will, in all likelihood, consider buying these products or brands to support sustainability practices. Hence, the authors formulate the sixth hypothesis as follows -

H6: Sustainability trust on social media positively influences the intention to purchase sustainable products.

Based on theoretical relationships and developed hypotheses, the theoretical framework shown in Fig. 1 consists of five constructs, i.e. sustainability-related information seeking (WSS), dependency on social media for sustainability-related 


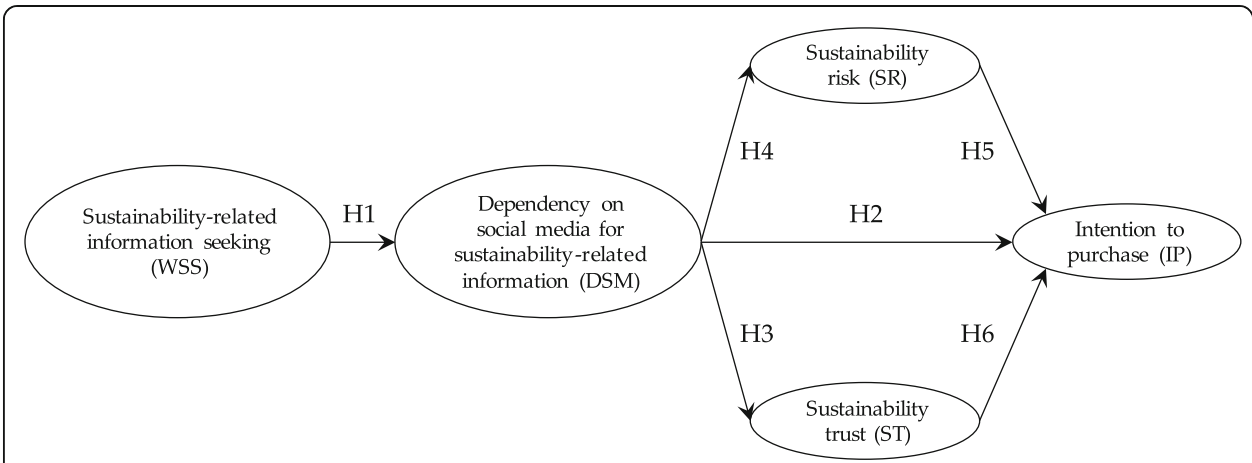

Fig. 1 Research Model - Source: Adapted (Ben Abdelaziz et al. 2015)

information (DSM), sustainability trust (ST), sustainability risk (SR), and intention to purchase (IP).

\section{Methodology and measurement}

\section{Data collection and sample size}

To the authors' best knowledge, this paper, which focuses on social media users residing in Pakistan, is one of the few empirical studies on consumers' purchase behavior in Pakistan that investigates the effects of sustainability-related information available on social media. In order to obtain data, the authors conducted an online survey, targeting the population aged between 18 and 55 years. Moreover, the authors offered complete anonymity to the survey participants. In order to complete the survey, it was mandatory for the participants to answer all the questions. Among 109 participants, the authors considered 91 responses for further analysis in which the participants answered all the survey questions.

Table 1 describes the sample's characteristics. The survey participants consisted of 49 (54\%) males and 42 (46\%) females. The majority of the survey respondents were highly educated with $49 \%$ having a bachelor's degree and 30\% a postgraduate degree. Most of the respondents, i.e. $46 \%$, were students by profession. Moreover, the vast majority of the survey participants (i.e. 89\%) were younger than the age of 35 years.

\section{Construct measurement}

The authors developed the survey based on previous scientific literature. In order to ensure a consistent understanding of the survey, the authors illustrated the meaning of sustainability in the social media context and they also illustrated sustainable product purchase in the survey's preface. In Table 2, the authors list survey items to measure each variable. The authors adopted a seven-point Likert scale to measure all questionnaire items ranging from strongly disagree (1) to strongly agree (7). However, the authors measured the sustainability risk and sustainability trust constructs using a seven-point Likert scale ranging from very unlikely (1) to very likely (7). In order to measure sustainabilityrelated information seeking, the authors adapted five items from Borah (2014). Furthermore, they adapted seven items of dependency on social media for sustainability-related information from Grant (1996). Moreover, they adapted five items of sustainability risk on 
Table 1 The sample's characteristics

\begin{tabular}{lll}
\hline Characteristics & $n=91$ & $\%$ \\
\hline Gender & & $54 \%$ \\
Male & 49 & $46 \%$ \\
Female & 42 & \\
Profession & & $46 \%$ \\
Student & 42 & $1 \%$ \\
Homemaker & 1 & $34 \%$ \\
Employed for wages & 31 & $9 \%$ \\
Self-employed & 8 & $3.3 \%$ \\
Out of work and looking for work & 3 & $2.2 \%$ \\
Out of work but not currently looking for work & 2 & $4.5 \%$ \\
Others & 4 & $42 \%$ \\
Age & & $33 \%$ \\
18-24years & 38 & $25 \%$ \\
$25-30$ years & 30 & $30 \%$ \\
30 years and above & 23 & $4.5 \%$ \\
Education & & $49 \%$ \\
Some high school & 4 & $12 \%$ \\
High school degree & 11 & \\
Some university course & 4 & 45 \\
University degree & 27 & \\
Postgraduate degree & & \\
\hline
\end{tabular}

social media, five items of sustainability trust on social media, and six items of intention to purchase from Chen and Chang (2012).

\section{Methodology}

After completing the data collection procedure to ensure data absoluteness, the authors cleaned the raw data. The data cleaning procedure ensures, for instance, that the collected data have no omissions, are consistent in classification, and are legible. The authors adopted the PLS-SEM approach for the data analysis and used SmartPLS 3 Professional software to analyze the data from 91 respondents. Scholars consider the PLS-SEM approach to analyze data, especially when dealing with a small sample size (Gefen and Boudreau 2000; Hair et al. 2017), such as the sample size in the current research work. The PLS-SEM approach regrouped into two steps: During the first step, the researchers examined the measurement (outer) model's reliability and validity, and during the second step, they assessed the significance of path relationships and $R^{2}$ values in the structural (inner) model.

\section{Findings and analysis}

\section{Measurement model assessment}

In assessing the measurement model, all the items were loaded into their respective variables. According to Chin (1998), the loadings are significant when the value is at least 0.6 and ideally at least 0.70 or more. A loading value of 0.70 means that the 
Table 2 Items for measuring each variable

\begin{tabular}{|c|c|c|}
\hline Construct & Measurement item & Reference \\
\hline $\begin{array}{l}\text { Sustainability-related information } \\
\text { seeking (WSS) }\end{array}$ & $\begin{array}{l}\text { WS1: Regarding sustainability issues, I seek more } \\
\text { information supporting my opinions. } \\
\text { WS2: Regarding sustainability issues, I seek more } \\
\text { information supporting the other opinions } \\
\text { WS3: Regarding sustainability issues, I seek more } \\
\text { information that offers a balanced view. } \\
\text { WS4: Regarding sustainability issues, I seek more } \\
\text { opinions supporting my point of view. } \\
\text { WS5: Regarding sustainability issues, I seek more } \\
\text { opinions supporting the other points of view. }\end{array}$ & $\begin{array}{l}\text { Borah } \\
(2014)\end{array}$ \\
\hline $\begin{array}{l}\text { Dependency on social media for } \\
\text { sustainability-related information } \\
\text { (DSM) }\end{array}$ & $\begin{array}{l}\text { Information available on social media helps me - } \\
\text { DSM1: decide whether to buy sustainable products/ } \\
\text { brands or not. } \\
\text { DSM2: decide which products/brands are sustainable } \\
\text { and which are not. } \\
\text { DSM3: decide whether to buy a certain sustainable } \\
\text { product/brand or not. } \\
\text { DSM4: know what sustainable } \\
\text { products/brands make good impressions on others. } \\
\text { DSM5: decide what sustainable products/brands to buy. } \\
\text { DSM6: decide between different sustainable products/ } \\
\text { brands alternatives. } \\
\text { DSM7: choose the right sustainable product/brand. }\end{array}$ & $\begin{array}{l}\text { Grant } \\
(1996)\end{array}$ \\
\hline Sustainability risk (SR) & $\begin{array}{l}\text { When I read negative statements by other users on social } \\
\text { media about a certain product/brand with respect to } \\
\text { its sustainability characteristics, I would likely suspect that - } \\
\text { SR1: the product/brand will not meet the desired } \\
\text { sustainability criteria. } \\
\text { SR2: the product/ brand will not work properly with } \\
\text { respect to sustainability requirements. } \\
\text { SR3: I would face negative consequences if I use this } \\
\text { product/brand, because of social or environmental harm. } \\
\text { SR4: using the product/brand will negatively affect sustainability } \\
\text { aspects (e.g., environment, work conditions, etc.) } \\
\text { SR5: using the product/brand would damage my reputation } \\
\text { or image as a person who cares about sustainability. }\end{array}$ & $\begin{array}{l}\text { Chen and } \\
\text { Chang } \\
\text { (2012) }\end{array}$ \\
\hline Sustainability trust (ST) & $\begin{array}{l}\text { When I read positive statements by other users on social media } \\
\text { about a certain product/brand with respect to its sustainability } \\
\text { characteristics, I would likely think that - } \\
\text { ST1: the product/brand's sustainability reputation is generally } \\
\text { reliable. } \\
\text { ST2: the product/brand will work properly with respect to } \\
\text { sustainability requirements. } \\
\text { ST3: the product/brand's claims regarding sustainability are } \\
\text { generally trustworthy. } \\
\text { ST4: the product/brand's concerns about sustainability meet } \\
\text { my expectations. } \\
\text { ST5: the product/brand keeps promises and commitments } \\
\text { regarding sustainability. }\end{array}$ & $\begin{array}{l}\text { Chen and } \\
\text { Chang } \\
\text { (2012) }\end{array}$ \\
\hline Intention to purchase (IP) & $\begin{array}{l}\text { IP1: I intend to purchase sustainable products/brands, because } \\
\text { of their sustainability concerns. } \\
\text { IP2: I expect to purchase sustainable products/brands in the } \\
\text { near future. } \\
\text { IP3: I avoid buying products/brands that are potentially } \\
\text { unsustainable. } \\
\text { IP4: Overall, I am glad to purchase sustainable products/brands, } \\
\text { because they are sustainable. } \\
\text { IP5: When I have to choose between two similar products/ } \\
\text { brands, I choose the one that is more sustainable. } \\
\text { IP6: I will not consider sustainability-related issues when making } \\
\text { a purchase. }\end{array}$ & $\begin{array}{l}\text { Chen and } \\
\text { Chang } \\
(2012)\end{array}$ \\
\hline
\end{tabular}


variable explains at least $50 \%$ of its related indicator's variance. The results in Table 3 show that, for the larger part, the items' loadings were satisfactory. However, the loading values of the third item of sustainability-related information seeking (WS3), the fourth item of dependency on social media for sustainability-related information (DSM4), the third item of sustainability risk (SR3), and the sixth item of intention to purchase (IP6) showed that these items were not loaded into their respective constructs. In other words, these items did not represent their respective constructs. Hence, the authors deleted these items, owing to low factor loadings. However, following the recommendations of Hair et al. (2017), the authors retained five items, - i.e. IP1, IP3, DSM1, DSM5, and SR1, - although their boasting outer loadings were below 0.70. The authors included these items in the analysis, particularly in order to avoid the loss of content that would have resulted from their deletion.

The variance inflation factor (VIF) test measures the value of excessive multicollinearity among the constructs and examines the level of collinearity. In the PLSSEM context, a VIF value of 5.0 or higher indicates a potential collinearity issue (Hair et al. 2017). Table 3 shows that all the VIF values for the current model are below 5.0, ranging from 1.2 to 2.8, which indicates that the model satisfied Hair et al. (2017)'s recommendation regarding collinearity.

Table 3 Loadings and variance inflation factor (VIF)

\begin{tabular}{|c|c|c|c|c|c|c|}
\hline & DSM & IP & $S R$ & ST & WSS & VIF \\
\hline DSM1 & 0.633 & & & & & 1.286 \\
\hline DSM2 & 0.769 & & & & & 2.240 \\
\hline DSM3 & 0.705 & & & & & 2.063 \\
\hline DSM5 & 0.695 & & & & & 1.619 \\
\hline DSM6 & 0.720 & & & & & 1.712 \\
\hline DSM7 & 0.755 & & & & & 1.781 \\
\hline IP1 & & 0.660 & & & & 1.342 \\
\hline IP2 & & 0.805 & & & & 1.619 \\
\hline IP3 & & 0.686 & & & & 1.412 \\
\hline IP4 & & 0.827 & & & & 2.789 \\
\hline IP5 & & 0.764 & & & & 2.453 \\
\hline SR1 & & & 0.646 & & & 1.468 \\
\hline SR2 & & & 0.765 & & & 1.521 \\
\hline SR4 & & & 0.837 & & & 1.721 \\
\hline SR5 & & & 0.796 & & & 1.427 \\
\hline ST1 & & & & 0.730 & & 1.557 \\
\hline ST2 & & & & 0.833 & & 1.983 \\
\hline ST3 & & & & 0.807 & & 2.403 \\
\hline ST4 & & & & 0.793 & & 1.884 \\
\hline ST5 & & & & 0.817 & & 2.401 \\
\hline WS1 & & & & & 0.754 & 1.739 \\
\hline WS2 & & & & & 0.761 & 1.929 \\
\hline WS4 & & & & & 0.767 & 1.407 \\
\hline WS5 & & & & & 0.791 & 1.651 \\
\hline
\end{tabular}


In accordance with Hair et al. (2017), Table 4 presents the measures of internal consistency reliability (Cronbach's alpha and Composite reliability) and convergent validity (AVE values). The composite reliability values for the current model ranged from 0.848 to 0.897 and Cronbach's values ranged from 0.773 to 0.856 , which are higher than the minimum acceptable limit of 0.70 to establish the model's reliability. In order to assess the convergent validity, the authors used the average variance extracted (AVE). An AVE value of 0.50 or more indicates that, on average, the construct explains more than half of the variance of its indicators (Hair et al. 2017). In the current model, the authors noted that all AVE values were higher than the acceptable range of 0.50 .

Discriminant validity is the extent to which a construct is truly distinct from other constructs by empirical standards (Hair et al. 2017). To assess the discriminant validity, the authors used the Fornell-Larcker (see Table 5) and Heterotrait-Monotrait Ratio of Correlations (HTMT) (see Table 6) criteria. The Fornell-Larcker criterion compares the square root of the AVE values with the latent variable correlations. It suggests that the square root of each construct's AVE should be greater than its highest correlation with any other construct, such that a construct shares more variance with its indicators than with the ones of any other construct in the model (Hair et al. 2017). The results in Table 5 asserts the discriminant validity as the square root of AVE for each latent variable (diagonal values) is higher than the other correlation values among the latent variables.

Furthermore, the results indicate that all HTMT values were below Hair et al. (2017)'s recommended value of 0.90, which satisfied the condition of the constructs' discriminant validity. Moreover, none of the values demonstrated a negative relationship between the respective variables.

\section{Structural model assessment (path analysis)}

The authors assessed the structural model using the coefficient of determination $\left(\mathrm{R}^{2}\right)$ and path coefficients. Based on the six direct relationship hypotheses, they analyzed the current model using PLS-SEM. Figure 2 presents the $R^{2}$ values for each exogenous variable. Academics consider an $R^{2}$ value of 0.20 high in the consumer behavior discipline (Hair et al. 2017). The authors estimated the highest $R^{2}$ for IP, i.e. 0.483, followed by ST, i.e. 0.249 , DSM, i.e. 0.185 , and SR, i.e. 0.028 . The $R^{2}$ values for two out of the four endogenous variables show that these variables were well explained by their relationships. The $R^{2}$ values for DSM were near the acceptable range. However, the $R^{2}$ values for SR showed that SR is not well explained by their relationships.

Table 7 presents the results of the effect sizes ( $f^{2}$ statistic). The results of the direct relation hypotheses in the current study show that the strongest effect size $\left(f^{2}=0.331\right)$

Table 4 Reliability and validity coefficients

\begin{tabular}{llll}
\hline & Cronbach's alpha & Composite reliability & Average variance extracted (AVE) \\
\hline DSM & 0.807 & 0.862 & 0.510 \\
IP & 0.806 & 0.865 & 0.564 \\
SR & 0.775 & 0.848 & 0.585 \\
ST & 0.856 & 0.897 & 0.635 \\
WSS & 0.773 & 0.852 & 0.590 \\
\hline
\end{tabular}


Table 5 Discriminant validity assessment (Fornell-Larcker criterion)

\begin{tabular}{llllll}
\hline & DSM & IP & SR & ST & WSS \\
\hline DSM & 0.714 & & & & \\
IP & 0.590 & 0.751 & & & \\
SR & 0.166 & 0.305 & 0.765 & 0.797 & \\
ST & 0.499 & 0.566 & 0.135 & 0.416 & 0.768 \\
WSS & 0.430 & 0.363 & 0.254 & & \\
\hline
\end{tabular}

with a t-value (5.653) was for dependency on social media for sustainability-related information on sustainability trust on social media, whereas, the authors considered the effect size $\left(f^{2}=0.028\right)$ with a t-value (1.179) for dependency on social media for sustainability-related information on sustainability risk on social media too small and therefore deemed it insignificant. Furthermore, the authors considered the following significant: the effect size $\left(f^{2}=0.212\right)$ and $\mathrm{t}$-value $(4.752)$ for dependency on social media for sustainability-related information on the intention to purchase, the effect size $\left(f^{2}=0.227\right)$ and $t$-value (6.189) for a willingness to seek sustainability-related information on dependency on social media for sustainability-related information, the effect size $\left(f^{2}=0.071\right)$ and $\mathrm{t}$-value $(2.677)$ for sustainability risk on social media on the intention to purchase, and the effect size $\left(f^{2}=0.175\right)$ and $\mathrm{t}$-value (4.117) for sustainability trust on social media on the intention to purchase.

The authors present the estimated values for the path coefficients in the structural model in Table 7. The result of $H 1$ (WSS $\rightarrow D S M$ ) shows that the hypothesis is accepted at the value of 0.430 for the path coefficient with a $p$-value of 0.000 and $t$-value of 6.189. Since the path coefficient is above the threshold value of 0.20 suggested by Hair et al. (2017), the results of $H 2(D S M \rightarrow I P)$ likewise shows that $\mathrm{H} 2$ is accepted at the value of 0.384 for the path coefficient with a $p$-value of 0.000 and $\mathrm{t}$-value of 4.752 . The result of $H 3(D S M \rightarrow S T)$ shows that it is accepted at the value of 0.499 for the path coefficient with a $p$-value of 0.000 and $\mathrm{t}$-value of 5.653. The result of $H 4(D S M \rightarrow S R)$ shows that it is rejected at the value of 0.166 for the path coefficient with a $p$-value of 0.239 and $\mathrm{t}$-value of 1.179 . The result of $H 5(S R \rightarrow I P)$ shows that it is accepted at the value of 0.194 for the path coefficient with a $p$-value of 0.008 and $t$-value of 2.677. Similarly, the result of $H 6(S T \rightarrow I P)$ shows that it is accepted at the value of 0.348 for the path coefficient with a $p$-value of 0.000 and $t$-value of 4.117 .

To conclude, the hypotheses resulting from a t-value higher than 1.96 and $p$-value less than 0.05 lead to the acceptance of hypotheses. All the hypotheses ( $H 1, H 2, H 3$, $H 5$, and H6) are accepted, except $H 4$.

Table 6 Discriminant validity assessment (HTMT criterion)

\begin{tabular}{llllll}
\hline & DSM & $\mathbb{P}$ & SR & ST & WSS \\
\hline DSM & & & & \\
IP & 0.703 & & & \\
SR & 0.230 & 0.362 & & \\
ST & 0.584 & 0.662 & 0.160 & 0.488 \\
WSS & 0.528 & 0.450 & 0.330 & \\
\hline
\end{tabular}




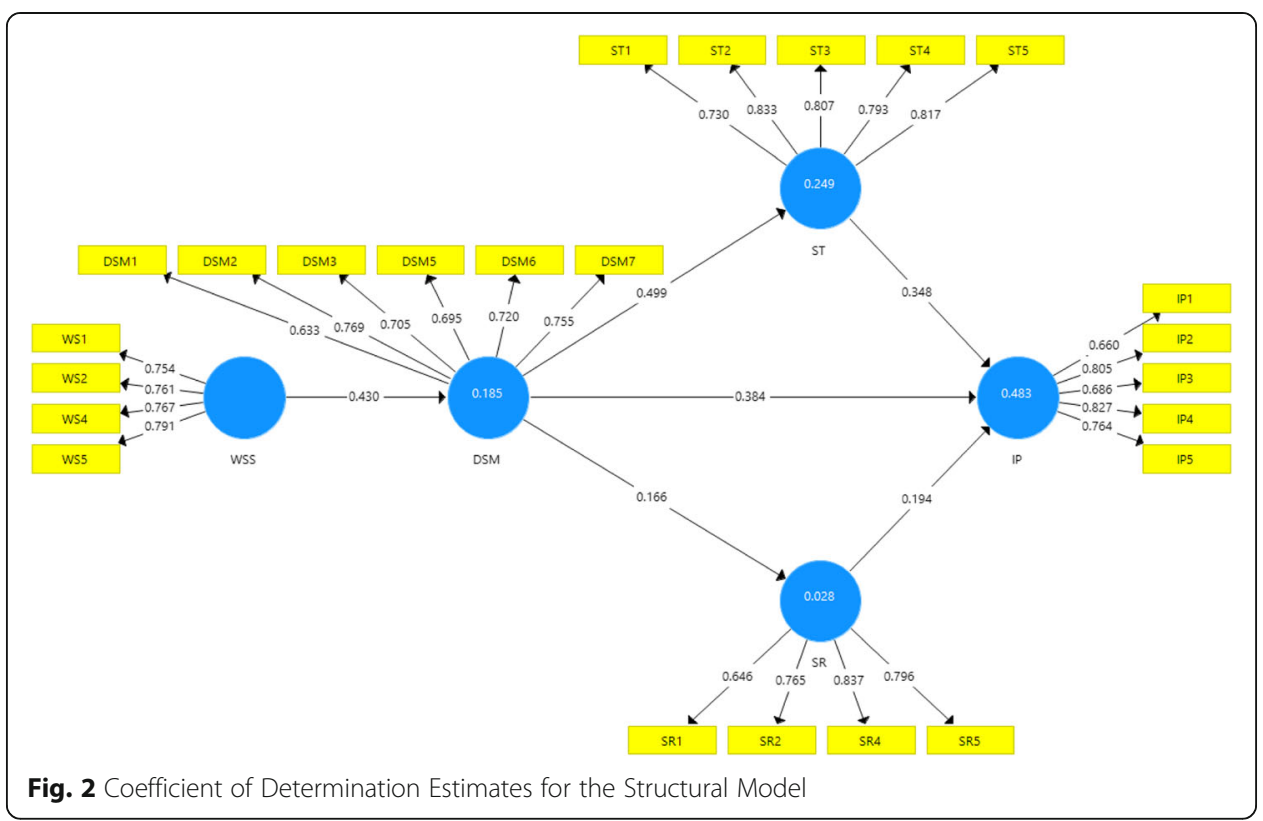

\section{Conclusions and outlook}

This article's main objective was to examine how sustainability-related information available on social media affects consumers' purchase behavior. To address the research question, the authors conducted an online survey of social media users residing in Pakistan and analyzed the collected data using PLS-SEM. The research results indicate that social media developed as an anchor point on the internet (Wang et al. 2016) for sustainability-related information sharing and, in turn, have the ability to influence consumers' intention to purchase. The integrated model's analyses with regard to social media dependency of consumers from a developing country, i.e. Pakistan in this research paper, help researchers understand the purchase intention behaviors, considering the trend of increased sustainability-related information acquisition via social media. This kind of social influence plays a vital role in shaping consumer behavior

Table 7 Results of direct relationship hypotheses

\begin{tabular}{|c|c|c|c|c|c|}
\hline Hypothesis & Path & $\begin{array}{l}\text { Path } \\
\text { coefficient }\end{array}$ & $\begin{array}{l}\text { t- } \\
\text { Value }\end{array}$ & $\begin{array}{l}p^{-} \\
\text {Value }\end{array}$ & Finding \\
\hline $\begin{array}{l}\text { H1: Willingness to seek sustainability-related information } \\
\text { positively influences the dependency on social media for } \\
\text { sustainability-related information. }\end{array}$ & WSS $\rightarrow$ DSM & 0.430 & 6.189 & 0.000 & Accepted \\
\hline $\begin{array}{l}\text { H2: Dependency on social media for sustainability-related } \\
\text { information positively influences the intention to purchase } \\
\text { sustainable products. }\end{array}$ & $\mathrm{DSM} \rightarrow \mathrm{P}$ & 0.384 & 4.752 & 0.000 & Accepted \\
\hline $\begin{array}{l}\text { H3: Dependency on social media for sustainability-related } \\
\text { information positively influences sustainability trust on social } \\
\text { media. }\end{array}$ & $\mathrm{DSM} \rightarrow \mathrm{ST}$ & 0.499 & 5.653 & 0.000 & Accepted \\
\hline $\begin{array}{l}\text { H4: Dependency on social media for sustainability-related } \\
\text { information positively influences sustainability risk on social } \\
\text { media. }\end{array}$ & $\mathrm{DSM} \rightarrow \mathrm{SR}$ & 0.166 & 1.179 & 0.239 & Rejected \\
\hline $\begin{array}{l}\text { H5: Sustainability risk on social media positively influences } \\
\text { the intention to purchase sustainable products. }\end{array}$ & $\mathrm{SR} \rightarrow \mathrm{P}$ & 0.194 & 2.677 & 0.008 & Accepted \\
\hline $\begin{array}{l}\text { H6: Sustainability trust on social media positively influences } \\
\text { the intention to purchase sustainable products. }\end{array}$ & $\mathrm{ST} \rightarrow \mathrm{P}$ & 0.348 & 4.117 & 0.000 & Accepted \\
\hline
\end{tabular}


(Ronald et al. 2019) with regard to a preference for purchasing sustainable products. Moreover, this article distinguishes between the product sustainability trust and product sustainability risk associated with the intention to purchase.

The results of this research paper reveal that consumers' willingness to seek sustainability-related information lead them to consider social media platforms as a key source of sustainability-related information. Besides, the authors found that the consumers' intention to purchase was subject to their dependency on social media for sustainability-related information. This means that consumers who depend on social media are more likely to purchase sustainable products. This proves that social media users are a relevant customer segment and that social media is a good place to target potential consumers of sustainable products. The results also show that social media dependency has a positive effect on perceived trust, i.e. positive sustainability-related information about products. This means that consumers who depend on social media for sustainability-related information are more likely to adopt positive WOM on social media with regard to product sustainability, which positively influences consumers' intention to purchase. However, consumers' dependency on social media for sustainability-related information does not make them more prone to negative WOM on social media. Nonetheless, susceptibility to negative WOM on social media has a positive effect on the intention to purchase sustainable products. Hence, it is possible to interpret users' proneness to negative and positive WOM on social media as exhibiting a stronger commitment to sustainability and, therefore, a higher likelihood to purchase sustainable products.

In accordance with these research results, the authors can propose that businesses should also start focusing on the content that is available on social media platforms regarding their products, and that they should acquaint themselves with electronic word of mouth (eWOM). It has become essential to comprehend different factors that act as antecedents and that can affect human behaviors, such as purchase behavior, as a result of social media usage (Wang et al. 2016). In this context, this article recommends that businesses should pay more attention to developing their brands on social media and establishing their relationships with individual users and potential consumers, such that they can remain in contact with their customers in order to fulfill their needs.

Furthermore, consumers' dependency on social media for seeking sustainabilityrelated information about products has no effect in the case of negative WOM or perceived sustainability risk, i.e. consumers' social media dependency does not increase their sensitivity to negative WOM on social media. However, consumers in Pakistan are prone to negative statements on social media regarding a product's sustainability performance, i.e. negative WOM on social media has a negative effect on their intention to purchase. Interestingly, in the case of developed countries, such as Germany, the observations were rather different. In their study, Ben Abdelaziz et al. (2015) noticed that consumers in Germany depend on social media when it comes to sustainability-related information seeking, and consumers' sensitivity to negative, as well as positive, WOM on social media increased according to their social media dependency. However, Ben Abdelaziz et al. (2015)'s study noted that, in Germany, the effect of negative sustainability-related information or perceived sustainability risk on the intention to purchase was insignificant. 
To conclude, it is possible to argue in this article that sustainability-related information on social media has the potential to influence consumers' intention to purchase sustainable products or brands in developing countries like Pakistan. Furthermore, social media has emerged as an essential platform for seeking sustainability-related information in developed (e.g., Germany) (Ben Abdelaziz et al. 2015) and developing (e.g., Pakistan) countries, and positive WOM on social media regarding products' or brands' sustainability performance positively influences consumers' intention to purchase.

Moreover, to a great extent, managers might find sustainable trust and sustainable risk on social media interrelated in the context where a decrease in customers' perceived risk with regard to sustainable products can help ease customers' perception to raise product sustainability trust. Based on this study's findings, the authors can conclude that firms should put more emphasis on producing sustainable products, considering that sustainable trust and sustainable risk on social media impact consumers' intention to purchase. Practitioners and policymakers should also focus on communicating their products' sustainability features effectively to shape the customers' attitude and behaviors, which can help organizations create a positive image of their products and brands (Joshi and Rahman 2015). Consequently, the authors postulate that companies can produce customers' trust and intention to purchase sustainable products by increasing their companies' presence on social media platforms to provide more awareness of their products' sustainability and communicate more about their sustainabilityrelated efforts and achievements (e.g., certifications awarded) (Rahbar and Abdul Wahid 2011). Furthermore, industrial corporations and brands can build more customers' trust by providing reliable, sustainability-related information about their products in a simple and user-friendly manner (Joshi and Rahman 2015). Moreover, the presence of companies on social media platforms, building direct relationships with consumers, and handling consumers' queries on social media are also considered helpful to gain customers' trust (Goh et al. 2013) and increase their intention to purchase.

Academicians can conduct further research to understand the factors and mechanisms that influence individuals' purchase behavior based on their dependency on social media platforms for seeking sustainability-related information in developed and developing countries. Furthermore, academics can conduct an in-depth study of the framework that the authors propose in this research paper by including other related factors, such as sustainability-related confusion and sustainability involvement from the perspective of developed and developing countries. Moreover, scholars can also expand future research via a longitudinal research methodology in order to investigate the value of sustainability-related information on social media about a product or brand over a relatively long period of time.

Acknowledgments

Not applicable.

\section{Authors' contributions}

Conceptualization, MAS, WK, and SIBA; methodology, MAS, AF; software, MAS and AF; validation, MAS, AF, and SIBA; formal analysis, MAS and AF; investigation, MAS and AF; resources, WK; data curation, MAS and AF; writing - original draft preparation, MAS and AF; writing — review and editing, MAS, AF, WK and SIBA; project administration, MAS and WK. All authors read and approved the final manuscript. 
Availability of data and materials

The datasets generated during and/or analyzed during the current study are available from the corresponding author on reasonable request.

\section{Competing interests}

The authors declare that they have no competing interests.

\section{Author details}

${ }^{1}$ Hamburg University of Technology, Institute of Business Logistics and General Management, Am Schwarzenberg Campus 4, 21073 Hamburg, Germany. ${ }^{2}$ University of Management and Technology, Lahore, Pakistan.

Received: 21 June 2019 Accepted: 21 September 2019

Published online: 17 October 2019

\section{References}

Altarawneh M (2013) Consumer awareness towards organic food: a pilot study in Jordan. J Agric Food Technol 3:14-18 Ball-Rokeach SJ, DeFleur ML (1976) A dependency model of mass-media effects. Commun Res 3:3-21. https://doi.org/10. 1177/009365027600300101

Ben Abdelaziz SI, Saeed MA, Benleulmi AZ (2015) Social media effect on sustainable products purchase. In: Kersten W, Blecker T, Ringle CM (eds) Innovations and strategies for logistics and supply chains: technologies, business models and risk management, 1st edn. Epubli GmbH, Berlin, pp 64-93

Berger R (2014) Socialize your business: ten things executives should know about digitalization and social media beyond. Roland Berger Strategic Consultants, Munich

Borah P (2014) The hyperlinked world: a look at how the interactions of news frames and hyperlinks influence news credibility and willingness to seek information. J Comput-Mediat Commun 19:576-590. https://doi.org/10.1111/jcc4.12060

Brown J, Broderick AJ, Lee N (2007) Word of mouth communication within online communities: conceptualizing the online social network. J Interact Mark 21:2-20. https://doi.org/10.1002/dir.20082

Butt A (2017) Determinants of the consumers green purchase intention in developing countries. J Manage Sci 4:217-236. https://doi.org/10.20547/jms.2014.1704205

Buzzetto-More N (2013) Social media and prosumerism. Issues in Informing Science and Information Technology, vol 10, pp 1-14

Carillo K, Scornavacca E, Za S (2017) The role of media dependency in predicting continuance intention to use ubiquitous media systems. Inf Manag 54:317-335. https://doi.org/10.1016/j.im.2016.09.002

Carter CR, Easton PL (2011) Sustainable supply chain management: evolution and future directions. Int J Phys Distrib Logistics Manage 41:46-62. https://doi.org/10.1108/09600031111101420

Chang HH, Chen SW (2008) The impact of online store environment cues on purchase intention: trust and perceived risk as a mediator. Online Inf Rev 32:818-841. https://doi.org/10.1108/14684520810923953

Chang MK, Cheung W, Tang M (2013) Building trust online: interactions among trust building mechanisms. Inf Manag 50: 439-445. https://doi.org/10.1016/j.im.2013.06.003

Chen Y-S, Chang C-H (2012) Enhance green purchase intentions. Manag Decis 50:502-520. https://doi.org/10.1108/ 00251741211216250

Cheung CMK, Thadani DR (2012) The impact of electronic word-of-mouth communication: a literature analysis and integrative model. Decis Support Syst 54:461-470. https://doi.org/10.1016/j.dss.2012.06.008

Chin WW (1998) Commentary: issues and opinion on structural equation modeling. MIS Q 22(1):vii-xvi. https://www.jstor.org/ stable/249674?seq=1\#page_scan_tab_contents

Darley WK, Johnson DM (1993) Cross-national comparison of consumer attitudes toward consumerism in four developing countries. J Consum Aff 27:37-54. https://doi.org/10.1111/j.1745-6606.1993.tb00736.x

Dei Worldwide (2008) Engaging consumers online: the impact of social media on purchasing behavior. https:// themarketingguy.files.wordpress.com/2008/12/dei-study-engaging-consumers-online-summary.pdf

Gáti M, Markos-Kujbus E (2012) Social media's new role in marketing communication and its opportunities in online strategy building. 4th European communication conference

Gefen D, Boudreau M-C (2000) Structural equation modeling and regression: guidelines for research practice. Commun Assoc Inf Syst 4. https://doi.org/10.17705/1CAIS.00407

Gleim MR, Smith JS, Andrews D, Cronin JJ Jr (2013) Against the green: a multi-method examination of the barriers to green consumption. J Retail 89:44-61. https://doi.org/10.1016/j.jretai.2012.10.001

Goh K-Y, Heng C-S, Lin Z (2013) Social media brand community and consumer behavior: quantifying the relative impact of user-and marketer-generated content. Inf Syst Res 24:88-107. https://doi.org/10.1287/isre.1120.0469

Grant AE (1996) Media dependency and multiple media sources. Psychol Pol Commun 199:210

Grégoire Y, Salle A, Tripp TM (2015) Managing social media crises with your customers: the good, the bad, and the ugly. Bus Horiz 58:173-182. https://doi.org/10.1016/j.bushor.2014.11.001

Hair JF, Hult GTM, Ringle CM, Sarstedt M (2017) A primer on partial least squares structural equation modeling (PLS-SEM), 2nd edn. SAGE Publications, Thousand Oaks

Hervani AA, Helms MM, Sarkis J (2005) Performance measurement for green supply chain management. Benchmarking: Int J 12:330-353. https://doi.org/10.1108/14635770510609015

ITU (2017) ICT facts and figures 2017. ICT Data and Statistics Division, Geneva

Jaiswal D, Kant R (2018) Green purchasing behaviour: a conceptual framework and empirical investigation of Indian consumers. J Retail Consum Serv 41:60-69. https://doi.org/10.1016/j.jretconser.2017.11.008

Jaiswal D, Singh B (2018) Toward sustainable consumption: investigating the determinants of green buying behaviour of Indian consumers. Bus Strategy Dev 1:64-73. https://doi.org/10.1002/bsd2.12

Joshi Y, Rahman Z (2015) Factors affecting green purchase behaviour and future research directions. Int Strateg Manage Rev 3:128-143. https://doi.org/10.1016/j.ism.2015.04.001 
Joshi Y, Rahman Z (2019) Consumers' sustainable purchase behaviour: modeling the impact of psychological factors. Ecol Econ 159:235-243. https://doi.org/10.1016/j.ecolecon.2019.01.025

Jung J, Moro M (2012) Cross-level analysis of social media: toward the construction of an ecological framework. J Soc Sci 73:53-74

Kaplan AM, Haenlein M (2010) Users of the world, unite!: The challenges and opportunities of social media. Bus Horiz 53:59-68. https://doi.org/10.1016/j.bushor.2009.09.003

Kheiravar S (2018) Exploring the acceptance of ubiquitous computing-based information services in brick and mortar retail environments-an integration of UTAUT2 and media system dependency theory. Hamburg University of Technology, Hamburg. https://doi.org/10.15480/882.1721

Kim DJ, Ferrin DL, Rao HR (2008) A trust-based consumer decision-making model in electronic commerce: the role of trust, perceived risk, and their antecedents. Decis Support Syst 44:544-564. https://doi.org/10.1016/j.dss.2007.07.001

KPMG (2015) Currents of change: the KPMG survey of corporate responsibility 2015. assets.kpmg.com/content/dam/kpmg/ pdf/2016/02/kpmg-international-survey-of-corporate-responsibility-reporting-2015.pdf. Accessed 30 Nov 2016

Ladhari R, Michaud M (2015) eWOM effects on hotel booking intentions, attitudes, trust, and website perceptions. Int J Hosp Manag 46:36-45. https://doi.org/10.1016/j.j.jhm.2015.01.010

Laroche M, Habibi MR, Richard M-O, Sankaranarayanan R (2012) The effects of social media based brand communities on brand community markers, value creation practices, brand trust and brand loyalty. Comput Hum Behav 28:1755-1767. https://doi.org/10.1016/j.chb.2012.04.016

Men LR, Tsai W-HS (2013) Beyond liking or following: understanding public engagement on social networking sites in China. Public Relat Rev 39:13-22. https://doi.org/10.1016/j.pubrev.2012.09.013

Mitchell V-W, Papavassiliou V (1999) Marketing causes and implications of consumer confusion. J Prod Brand Manag 8:319-342. https://doi.org/10.1108/10610429910284300

Mohiuddin M, Al Mamun A, Syed F, Mehedi Masud M, Su Z (2018) Environmental knowledge, awareness, and business school students' intentions to purchase green vehicles in emerging countries. Sustainability 10:1534. https://doi.org/10. 3390/su10051534

Ngai EWT, Tao SSC, Moon KKL (2015) Social media research: theories, constructs, and conceptual frameworks. Int J Inf Manag 35:33-44. https://doi.org/10.1016/j.jijnfomgt.2014.09.004

Nielsen (2015) The sustainability imperative: new insights on consumer expectations. http://www.nielsen.com/content/dam/ corporate/us/en/reports-downloads/2015-reports/global-sustainability-report-oct-2015.pdf. Accessed 9 Mar 2016

Petersen M (2017) Considering sustainability in the development of consumer goods. Hamburg University of Technology, Hamburg. https://doi.org/10.15480/882.1357

Rahbar E, Abdul Wahid N (2011) Investigation of green marketing tools' effect on consumers' purchase behavior. Bus Strategy Ser 12:73-83. https://doi.org/10.1108/17515631111114877

Reilly A, Weirup A (2012) Sustainability initiatives, social media activity, and organizational culture: an exploratory study. J Sustainability Green Bus 57:1-15

Ribeiro FM, Kruglianskas I (2013) Improving environmental permitting through performance-based regulation: a case study of Sao Paulo state, Brazil. J Clean Prod 46:15-26. https://doi.org/10.1016/j.jclepro.2012.09.017

Ronald CA, Haytko DL, Hermans CM, Simmers CS (2019) Social influence on green consumerism: country and gender comparisons between China and the United States. J Int Consum Mark 79:1-14. https://doi.org/10.1080/08961530.2018.1527740

Saeed MA, Kersten W (2017) Supply chain sustainability performance indicators - a content analysis based on published standards and guidelines. Logistics Res 10:1-19. https://doi.org/10.23773/2017_12

Saeed MA, Kersten W (2019) Drivers of sustainable supply chain management: identification and classification. Sustainability 11:1137. https://doi.org/10.3390/su1 1041137

Seuring S, Müller M (2008) From a literature review to a conceptual framework for sustainable supply chain management. J Clean Prod 16:1699-1710. https://doi.org/10.1016/j.jclepro.2008.04.020

Statista (2019) Global digital population as of April 2019 (in millions). https://www.statista.com/statistics/617136/digitalpopulation-worldwide/

Wang C-Y, Lee H-C, Wu L-W, Liu C-C (2017) Quality dimensions in online communities influence purchase intentions. Manag Decis 55:1984-1998. https://doi.org/10.1108/MD-11-2016-0822

Wang Y, Min Q, Han S (2016) Understanding the effects of trust and risk on individual behavior toward social media platforms: a meta-analysis of the empirical evidence. Comput Hum Behav 56:34-44. https://doi.org/10.1016/j.chb.2015.11.011

Xiang Z, Gretzel U (2010) Role of social media in online travel information search. Tour Manag 31:179-188. https://doi.org/10. 1016/j.tourman.2009.02.016

\section{Publisher's Note}

Springer Nature remains neutral with regard to jurisdictional claims in published maps and institutional affiliations. 